\title{
PARTICIPAÇÃO FEMININA NO CONSELHO DE ADMINISTRAÇÃO E A SUSTENTABILIDADE EMPRESARIAL
}

\section{FEMALE PARTICIPATION ON THE BOARD OF DIRECTORS AND ITS INFLUENCE ON CORPORATE SUSTAINABILITY}

\author{
ÍTALO CARLOS SOARES DO NASCIMENTO \\ Universidade Federal do Ceará (UFC) \\ Mestre em Administração e Controladoria pela Universidade Federal do Ceará (UFC) \\ Orcid: https://orcid.org/0000-0002-8151-696X / E-mail: italocarlos25@gmail.com \\ Endereço: Av. da Universidade, 2431, Benfica, Fortaleza/CE, CEP: 60020-180

\section{ADRIANO FLECK DE PAULA PESSOA} \\ Universidade Federal do Ceará (UFC) \\ Mestre em Administração e Controladoria pela Universidade Federal do Ceará (UFC) \\ Orcid: https://orcid.org/0000-0002-1846-5944 / E-mail: adrianofleck@uol.com.br
}

\author{
ALESSANDRA CARVALHO DE VASCONCELOS \\ Professora da Universidade Federal do Ceará (UFC) \\ Doutora em Engenharia de Produção pela Universidade Federal de Santa Catarina (UFSC) \\ Orcid: https://orcid.org/0000-0002-6480-5620 / E-mail: alevasconcelos.ufc@gmail.com \\ MÁRCIA MARTINS MENDES DE LUCA \\ Professora da Universidade Federal do Ceará (UFC) \\ Doutora em Controladoria e Contabilidade pela Universidade de São Paulo (USP) \\ Orcid: https://orcid.org/0000-0002-9995-5637 / E-mail: marciammdeluca@gmail.com \\ Submissão: 14/04/2020. Revisão: 26/10/2020. Aceite: 11/01/2021. Publicação: 01/03/2021. \\ DOI: http://dx.doi.org/10.22277/rgo.v14i2.5381
}

\begin{abstract}
RESUMO
Fundamentado na Teoria dos Stakeholders, investiga-se a correlação entre a participação feminina no conselho de administração e a sustentabilidade empresarial, em 319 companhias listadas na B3. De natureza quantitativa, a pesquisa descritiva utilizou o teste de diferenças entre médias, a análise de correspondência múltipla e a regressão logística. A participação feminina é medida pela proporção do número de mulheres presentes no conselho em relação ao total de seus membros titulares, enquanto a proxy da sustentabilidade empresarial é mensurada a partir da participação da empresa em índices ou rankings de sustentabilidade. Os resultados indicam que as empresas sustentáveis são as que mais incluem mulheres no conselho de administração. Entretanto, os achados sugerem que a participação feminina ainda é baixa, corroborando estudos empíricos estrangeiros. Ao se confrontar as empresas sustentáveis com as demais, identificaram-se diferenças significantes no tocante à participação feminina no conselho de administração, permitindo-se concluir, com base na análise de regressão logística, que as empresas sustentáveis têm maior probabilidade de incluir mulheres no órgão colegiado, alinhando-se aos preceitos da Teoria dos Stakeholders, ao apontar que as mulheres têm uma maior preocupação com a sustentabilidade empresarial.
\end{abstract}

Palavras-chave: Teoria dos Stakeholders. Participação feminina. Conselho de administração. Sustentabilidade empresarial. 


\begin{abstract}
Based on the Stakeholders Theory, this study investigates the correlation between female participation in the board of directors and corporate sustainability within 319 companies listed in B3 (Brazil, Stock Exchange, and Over-the-Counter Market). This paper is a quantitative research. Descriptive research is used as well as the test of differences between means, the analysis of multiple correspondence and the logistic regression. Female participation is measured by the proportion of women on the board in relation to all members, while the proxy for corporate sustainability is measured by the company's participation in sustainability indexes or rankings. The results show that sustainable companies are the ones that most include women on the board. Despite this, the findings suggest that female participation is still low, and this supports foreign empirical studies. To confront sustainable companies with others, significant differences were identified regarding the female participation in the board of directors, allowing to conclude, based on logistic regression analysis, that sustainable companies are more likely to include women in the board of directors according to the Stakeholder Theory and concluding that women have a greater concern for corporate sustainability.
\end{abstract}

Keywords: Stakeholder Theory. Female participation. Board of Directors. Corporate sustainability.

\title{
1 INTRODUÇÃO
}

A governança corporativa, compreendida como um sistema pelo qual as empresas e demais organizações são dirigidas, monitoradas e incentivadas, envolvendo os relacionamentos entre sócios, conselho de administração, diretoria, órgãos de fiscalização e controle e demais partes interessadas (IBGC, 2015), deve se importar cada dia mais com a sustentabilidade empresarial e a adoção de boas práticas (GUIMARÃES; PEIXOTO; CARVALHO, 2017; HUSSAIN; RIGONI; ORIJI, 2018).

No entanto, as políticas organizacionais que abrangem essas dimensões são onerosas, e não produzem efeitos diretos nos resultados, razão pela qual nem sempre são prioridades para os executivos (KOEHN, 2013). Em vista disso, o conselho de administração, considerado o principal órgão de governança, que existe em todas as empresas de capital aberto, de caráter deliberativo, e integrado por profissionais eleitos pelos acionistas (ROSSETTI; ANDRADE, 2014), desempenha o importante papel de direcionar a estratégia empresarial e influenciar as decisões dos executivos (WESTPHAL; ZAJAC, 1995). Dentre essas estratégias, destaca-se a sustentabilidade empresarial, entendida como um conjunto de atividades que envolvem a relação da empresa com o ambiente, com a economia e com a sociedade, baseada no tripé de Elkington (2001), sendo esta a definição adotada pelo presente estudo.

Cabe ressaltar que desde a década de 1970, os problemas sociais e ambientais passaram a ter um peso maior em termos de políticas públicas e exigências para as empresas, além da questão econômica (ACKERMAN, 1975; MCDONALD; PUXTY, 1979). Foi nessa década que o conceito de sustentabilidade passou a ser desenvolvido como uma forma de encontrar um equilíbrio entre valores econômicos, ambientais e sociais, formando o conhecido tripé de Elkington (2001) - tripé da sustentabilidade, a partir da primeira conferência da Organização das Nações Unidas (ONU) sobre o homem e o meio ambiente (DE LUCA et al., 2014). Apesar de desde então já ser possível identificar exigências legais - pelos menos nos EUA e em países da Europa - para as empresas, somente após a segunda conferência da ONU sobre o tema, a 
Ítalo Carlos Soares do Nascimento, Adriano Fleck de Paula Pessoa, Alessandra Carvalho de Vasconcelos e Márcia Martins Mendes de Luca

Rio 1992, é que essa questão ganhou destaque mundial, passando a ter importância para a governança de grandes empresas, pois os stakeholders, incluindo acionistas e consumidores, passaram a cobrar práticas que ajudassem a resolver essas questões ambientais e sociais (DYLLICK; HOCKERTS, 2002).

Com grande interesse pela questão, as principais bolsas de valores do mundo, como as de Nova lorque, Londres e São Paulo, criaram índices baseados nessas três dimensões econômica, social e ambiental: Dow Jones Sustainability Index (DJSI), FTSE4Good e Índice de Sustentabilidade Empresarial (ISE), respectivamente. A importância dessa questão, fora a preocupação ambiental e social, também passa pelo próprio valor da empresa, que está cada dia mais relacionado com o interesse de toda a comunidade envolvida com as suas atividades, conforme preceitua a Teoria dos Stakeholders (JENSEN, 2002), a qual sustenta que as empresas, para garantir valor em longo prazo, necessitaram conciliar os interesses dos acionistas com empregados, clientes, fornecedores e da comunidade (GUIMARÃES; PEIXOTO; CARVALHO, 2017). Além disso, sob a ótica da Teoria dos Stakeholders a organização é um sistema de grupo de stakeholders, e sua continuidade está atrelada à capacidade que tem de cumprir sua finalidade econômica e social, gerando valor ou riqueza (CLARKSON, 1995).

Nesse contexto, o conselho de administração desempenha o papel de assessoramento sobre a governança corporativa, para que esta possa, de fato, monitorar e controlar, além do desempenho econômico da organização, suas ações voltadas para a sustentabilidade (KOLK, 2008). Assim, a qualidade da composição do conselho de administração revela-se fundamental para o desenvolvimento de estratégias organizacionais no sentido de valorizar a empresa perante o mercado e a sociedade. Neste sentido, o IBGC (2015) recomenda que um bom conselho de administração deve ser composto levando-se em consideração a diversidade de conhecimentos, experiências, comportamentos, aspectos culturais, faixa etária e de gênero. Especificamente no que diz respeito a diversidade de gênero, recomenda-se que a diretoria estabeleça e divulgue políticas que propiciem igualdade de oportunidades para o acesso de mulheres a posições de alta liderança na organização.

Dessa forma, alguns estudiosos estrangeiros trazem evidências empíricas de que os conselhos de administração com maior participação feminina tratam a sustentabilidade de uma forma diferenciada, com a sua melhor promoção (BOULOUTA, 2012; BYRON; POST, 2016; GALBREATH, 2011; GLASS; COOK; INGERSOLL, 2015; MAHMOOD et al., 2018; SIAL et al., 2018). Outros estudos demonstram que as mulheres integrantes de conselho de administração exercem maior impacto na performance e na governança corporativa da organização, já que apresentam melhor empenho e diferentes percepções em comparação com os homens (ADAMS; FERREIRA, 2009; GLASS; COOK, 2018; NISIYAMA; NAKAMURA, 2018; PLETZER et al., 2015; YAP, 2017), e porque representam melhor as necessidades de todos os stakeholders (BIGGINS, 1999).

Considerando-se que os membros do conselho de administração desempenham o papel de direcionar esforços de responsabilidade social e ambiental, com o objetivo de atender aos diversos stakeholders da organização (CARRASCO et al., 2015), e seguindo-se as evidências teóricas apresentadas, emerge a seguinte questão-problema: qual a correlação entre a participação feminina no conselho de administração e a sustentabilidade empresarial em companhias listadas na B3? Destarte, o estudo tem como objetivo geral investigar a correlação entre a participação feminina no conselho de administração e a sustentabilidade empresarial, em companhias listadas na bolsa de valores brasileira. Adicionalmente, buscouse verificar a associação entre participação feminina, sustentabilidade empresarial e governança corporativa. 
Para o alcance dos objetivos aqui delineados, foi realizada uma pesquisa descritiva, aplicando-se o teste de diferenças entre médias, a análise de correspondência múltipla e a regressão logística, com base nos dados do exercício social de 2016, extraídos da base Economática $^{\circledR}$ e do Formulário de Referência de 319 empresas listadas na B3, além de informações contidas em índices e rankings de sustentabilidade.

A sinergia entre os dois construtos - participação feminina no conselho de administração e sustentabilidade empresarial -, evidenciada especialmente em pesquisas estrangeiras, tem demonstrado a relevância deste debate. Além disso, o estudo tem como base os preceitos da Teoria dos Stakeholders, segundo a qual a organização deve se preocupar não só com o shareholders, mas também com os diferentes grupos envolvidos e seus interesses específicos (DONALDSON; PRESTON, 1995).

Destarte, esta pesquisa justifica-se por abordar temática atual, relevante e ainda pouco explorada em âmbito nacional. Espera-se, assim, contribuir para o aprofundamento e o avanço da discussão dessas questões no meio acadêmico, trazendo novas constatações e procurando preencher lacunas ainda existentes, especialmente no contexto brasileiro, por se tratar de um país emergente e considerando-se que a maioria das pesquisas já realizadas se deram em países desenvolvidos, diferenciando-se, portanto, dos estudos anteriores ao demonstrar como se dá a participação feminina na alta gestão de companhias brasileiras e a sua influência na sustentabilidade empresarial. Para o mercado, é notória a crescente discussão sobre a sustentabilidade empresarial e quais são os fatores que corroboram para essas práticas no ambiente corporativo. Entender a influência da diversidade do conselho de administração, especialmente no tocante a diversidade de gênero como parte desse processo é fundamental para as empresas que buscam crescimento, competitividade e continuidade, tendo em vista o engajamento com os seus diversos stakeholders. Destarte, com o estudo pretende-se avaliar se a presença de mulheres no conselho de administração de organizações brasileiras contribui para o desenvolvimento de boas práticas voltadas para a sustentabilidade.

\section{REFERENCIAL TEÓRICO}

\subsection{GOVERNANÇA E SUSTENTABILIDADE EMPRESARIAL}

Dentre suas várias funções, a governança corporativa serve também para assessorar a gestão da organização e garantir que suas estratégias e práticas estejam de acordo com os proprietários e interessados (JOHNSON; GREENING, 1999; FONSECA; SILVEIRA, 2016). Para os objetivos desta pesquisa, considera-se a governança corporativa como um sistema de valores e padrões de comportamento, segundo o qual as empresas têm responsabilidade tanto quanto aos seus objetivos de negócios como em relação aos interesses dos diversos stakeholders (COIMBRA, 2011).

A governança como sistema de valores e padrões de comportamento remete aos quatro princípios ou valores fundamentais: transparência, equidade, prestação de contas e responsabilidade corporativa, entendida como a incorporação de considerações sociais e ambientais na definição dos negócios e operações (IBGC, 2015) e, com isso, a companhia consegue obter credibilidade, atrair capital e se diferenciar no mercado (FERREIRA, 2004). Nota-se que a percepção de valor da empresa supera o seu resultado econômico, envolvendo os meios que ela utiliza para tal, e o impacto no ambiente e nos envolvidos (LAZONICK; O’SULLIVAN, 2000). 
Ítalo Carlos Soares do Nascimento, Adriano Fleck de Paula Pessoa, Alessandra Carvalho de Vasconcelos e Márcia Martins Mendes de Luca

A cada dia que passa, mais empresas estão deixando de lado a tradicional visão apenas financeira, para adotar uma abordagem que englobe as dimensões social e ambiental, atendendo ao tripé da sustentabilidade empresarial, segundo a qual as suas políticas, práticas e decisões devem levar em conta não só o desempenho econômico, mas também as consequências sociais e ambientais de suas atividades (KAKABADSE, 2007; SPEZAMIGLIO; GALINA; CALIA, 2016). Dessa forma, as ações voltadas para a sustentabilidade são influenciadas pela governança, por meio de seus mecanismos internos, e esta deve direcionar as estratégias da organização para atenderem a todos os interessados (HUMPHRIES; WHELAN, 2017; KOLK, 2008).

Dentre esses mecanismos, destaca-se o conselho de administração, principal órgão da governança, capaz de monitorar as ações dos gestores, além de mitigar os conflitos de agência, trazendo os interesses dos stakeholders para os objetivos corporativos (JOHN; SENBET, 1998). O conselho tem por objetivo principal viabilizar a maximização do retorno dos investimentos, para o que desenvolve e implementa estratégias, como a prospecção de novos negócios e a criação de vantagens competitivas, com foco no longo prazo (ADAMS; HERMALIN; WEISBACH, 2010). Dentre suas funções, destacam-se a normativa direcionamento da organização -, a administrativa, a fiscalização e o controle (IBGC, 2015).

A partir da década de 1970, a sustentabilidade se tornou temática relevante, passando a compor a pauta do planejamento de governos, empresas, ONGs e organismos internacionais (DYLLICK; HOCKERTS, 2002). Apesar de sua complexa conceituação, a sustentabilidade ficou conhecida como um conjunto de práticas que compreendem o equilíbrio entre os impactos econômicos, sociais e ambientais (FRANCO et al., 2015), formando o chamado tripé de Elkington (2001). Independentemente de até hoje muitas dessas práticas ainda não serem exigidas por lei, a Teoria dos Stakeholders fundamenta que as organizações devem adotar práticas que atendam não apenas aos interesses dos shareholders, mas também aos de toda a sociedade, que pode vir a ser impactada por ações irresponsáveis (DONALDSON; PRESTON, 1995). Ou seja, os gestores devem tomar suas decisões respeitando o bem-estar dos stakeholders, pois estes não são apenas meios para um fim empresarial (FREEMAN; MCVEA, 2001).

A Teoria dos Stakeholders se interessa pela natureza das relações entre a organização e seus stakeholders em termos de processos e resultados e ao processo de tomada de decisões dos gestores irresponsáveis (DONALDSON; PRESTON, 1995). Sob a ótica da referida teoria, o objetivo corporativo deve ser estabelecido como uma função voltada para o equilíbrio e a satisfação dos interesses de todos os públicos envolvidos com a firma (MACHADO FILHO, 2006). Logo, a existência de longo prazo das empresas depende do suporte e da aprovação dos stakeholders (JENSEN, 2002). A Teoria dos Stakeholders defende ainda que as organizações atendam às demandas mais relevantes das partes interessadas, mas que tenham como função-objetivo a maximização de valor em longo-prazo. Nesse contexto, visualiza-se a sustentabilidade empresarial, que envolve as frentes econômica, social e ambiental (GUIMARÃES; PEIXOTO; CARVALHO, 2017).

Como forma de mensurar a sustentabilidade empresarial, uma série de índices, rankings e recomendações foi criada por diversas organizações nacionais e estrangeiras, ONGs e bolsas de valores. Dentre esses índices, destaca-se o Dow Jones Sustainability Index (DJSI). Lançado em 1999 pela bolsa de valores de Nova lorque, o DJSI alia desempenho econômico, social e ambiental, e passou a indicar as principais organizações sustentáveis dos EUA (KNOEPFEL, 2001). 
Dois anos após a criação do DJSI, surgiu o FTSE4Good, que derivou do índice Financial Times Stock Exchange (FTSE), da Grã-Bretanha - do grupo de comunicação que edita o jornal Financial Times - o qual incorporou dados de países de várias regiões, como América, Ásia e Europa. Seguindo essa tendência, em 2004 foi criado o primeiro índice de sustentabilidade de um país emergente, o Socially Responsible Index (SRI) da bolsa de valores de Johanesburgo (GUAY; DOH; SINCLAIR, 2004). Em 2005, surge no Brasil o Índice de Sustentabilidade Empresarial (ISE), da Bolsa de Valores, Mercadorias e Futuros (BM\&FBovespa), com metodologia e produção a cargo da Fundação Getúlio Vargas. Para participar do ISE, a empresa deve cumprir algumas condições, sendo requisito obrigatório que sua ação seja uma das 200 com maior liquidez da bolsa de valores. Deve também responder um questionário com quesitos relacionados à sustentabilidade da organização. Até 40 empresas podem fazer parte do ISE durante todo o ano seguinte, quando são selecionadas novas companhias para atualização do ranking (MACHADO; MACHADO; CORRAR, 2009).

Paralelamente ao ISE, a BM\&FBovespa - agora denominada B3 S. A. Brasil, Bolsa, Balcão -, em parceria com o Banco Nacional de Desenvolvimento Econômico e Social (BNDES), criou um índice de sustentabilidade, o Índice Carbono Eficiente (ICO2), reunindo as companhias participantes do índice IBrX-50 que aceitaram participar dessa iniciativa, adotando práticas transparentes com relação a suas emissões de gases de efeito estufa (B3, 2017).

Além dos índices, destaca-se também o Guia Exame de Sustentabilidade, que publica o ranking das empresas que adotam as mais avançadas práticas sustentáveis no Brasil (FURLAN, 2013) para a análise de sustentabilidade organizacional. A Exame também publica o ranking das maiores e melhores empresas brasileiras. Apesar de ser mais orientado para a dimensão econômica, esse índice utiliza diversos critérios, incluindo os de sustentabilidade. Destaque-se também o ranking das 150 melhores empresas para trabalhar, da revista Você $S / A$, que ressalta a questão social, já que seu critério de enquadramento considera principalmente itens e vantagens do ponto de vista do trabalhador.

Desse modo, a governança corporativa desempenha importante papel para a adoção de práticas de sustentabilidade. Para que a empresa obtenha um bom desempenho corporativo e possa de fato atender a todas as dimensões do tripé Elkington, deve ter um conselho de administração independente e com diversidade (ECCLES; SALTZMAN, 2011). A maioria dos estudos sobre o conselho de administração ressalta a importância do perfil dos seus membros. Além disso, alguns estudos, principalmente de autores estrangeiros, têm destacado o papel das mulheres na alta gestão organizacional como meio de diferenciação e ganho em termos de práticas institucionais mais aceitas pelos stakeholders (NIELSEN; HUSE, 2010).

\subsection{PARTICIPAÇÃO FEMININA NO CA E A SUSTENTABILIDADE EMPRESARIAL}

O conselho de administração é o defensor das boas práticas de governança, como também o responsável pela orientação geral, definição da estratégia e monitoramento dos planos de ação da organização (IBGC, 2015; BORBA et al., 2019). O órgão também participa das decisões mais importantes na empresa (HENDRY; KIEL, 2004). Destarte, exerce poder substancial e responsabilidade na supervisão da empresa, exercendo influência na estratégia, que, por sua vez, afeta o desempenho corporativo (FAMA; JENSEN, 1983).

Por isso, é importante dispor de membros capacitados e comprometidos. Além disso, ressalta-se a composição do conselho como fator de valorização da empresa, pois há uma 
Ítalo Carlos Soares do Nascimento, Adriano Fleck de Paula Pessoa, Alessandra Carvalho de Vasconcelos e Márcia Martins Mendes de Luca

maior complementariedade de habilidades e diferentes enfoques entre os membros (ANCA; GABALDON, 2014; FERRERO-FERRERO; FERNÁNDEZ-IZQUIERDO; MUÑOZ-TORRES, 2015).

Dessa forma, busca-se uma diversidade na composição do conselho, que pode ser de independência, gênero e nacionalidade dos seus membros (HARO-DE-ROSARIO et al., 2017). Ressalte-se que o Código de Melhores Práticas de Governança Corporativa (IBGC, 2015) recomenda uma maior diversidade na composição do conselho. Quanto ao gênero, destaquese, como uma das principais vantagens, que as mulheres são capazes de facilitar o processo decisório e trazer diferentes perspectivas para o conselho, em comparação com aquele formado apenas por homens (ROSE, 2007).

Alguns estudos indicaram que as mulheres possuem outras percepções e melhor empenho do que os homens (ADAMS; FERREIRA, 2009; ARAYDDI; DAH; JIZI, 2016; KARTIKEYAN; PRIYADARSHINI, 2017). Outros mostram que as mulheres possuem maior sentimento altruístico, o que implica um comportamento organizacional mais sociável e preocupado com outros indivíduos, enquanto os homens são mais individualistas e competitivos (CAPPELLE et al., 2004; GILLIGAN, 1982). Isso posto, é de se acreditar que as mulheres têm maior preocupação com os interesses dos stakeholders, e não apenas com os dos shareholders, diferentemente dos homens, que focam mais em seus próprios interesses (BIGGINS, 1999; GROSSER; MOON, 2005). Considerando-se que a sustentabilidade é exigida pelos stakeholders - quando não, legalmente - e é adotada nas práticas e planejamento da organização (DYLLICK; HOCKERTS, 2002; LINNENLUECKE; GRIFFITHS, 2010), essa preocupação também passa a fazer parte da governança corporativa. Conforme evidenciado, o conselho de administração constitui parte vital para a adoção das boas práticas. Como também foi abordado, a diversidade do conselho pode ser benéfica para tal finalidade.

Apesar da escassez de pesquisas nacionais acerca desse relacionamento, alguns estudos estrangeiros comprovam que há uma correlação positiva entre mulheres no conselho de administração e a adoção de práticas de sustentabilidade por parte da organização. A maioria desses estudos adotou como base a Teoria dos Stakeholders. Galbreath (2011), por exemplo, correlacionou a participação de mulheres no conselho de administração com as questões de sustentabilidade corporativa, após analisar 151 empresas australianas no período de 2005 a 2007 e seus dados de sustentabilidade - crescimento econômico, gastos com redução de impactos ambientais negativos e RSC -, com a participação feminina no conselho de administração. O estudo sugere que há uma correlação positiva entre uma maior diversidade de gêneros na composição do conselho de administração e as políticas de sustentabilidade da organização. Isso implica um melhor relacionamento com stakeholders, com aumento da accountability e intensificação e melhoria das condutas éticas.

Boulouta (2012) examinou como um conselho de administração com mulheres afeta a performance social da empresa. Para isso, foram analisadas 126 empresas com ações negociadas na bolsa de valores de Nova lorque pertencentes ao S\&P500, por um período de cinco anos. Como conclusão, a autora indicou que há uma correlação positiva entre a maior diversidade de gêneros no conselho - mais mulheres - e ações sociais por parte da empresa.

Fernandez-Feijoo, Romero e Ruiz-Blanco (2014) investigaram a relação entre a divulgação de relatórios de sustentabilidade e a existência de pelo menos três mulheres no conselho de administração. Os resultados demonstram que em países com uma maior proporção de conselhos com pelo menos três mulheres, os níveis de divulgação de relatórios de sustentabilidade são mais altos. Glass, Cook e Ingerssoll (2015) analisaram os efeitos da performance ambiental de 500 empresas dos EUA em relação à participação de mulheres no conselho de administração e na diretoria por um período de 10 anos. Os autores concluíram 
que a empresa cuja participação feminina no conselho e na diretoria é maior que a dos homens possui uma forte correlação com as práticas voltadas para a sustentabilidade.

Rodríguez-Ariza et al. (2016) realizaram um estudo com 550 empresas internacionais, no período de 2004 a 2010, com o objetivo de comparar o papel da mulher em cargos de alta gestão em empresas familiares e não familiares, no tocante à promoção de práticas sustentáveis. Apesar de a maioria dos estudos associarem a presença feminina nos órgãos colegiados com maior comprometimento socialmente responsável, os resultados encontrados demonstraram que em empresas familiares, o compromisso com a RSC não varia significativamente com a presença de mulheres no conselho, pois elas tendem a se comportar de acordo com a orientação da família.

Destaque-se também o estudo de Ben-Amar, Chang e Mcilkenny (2017), envolvendo empresas do Canadá. Foram analisadas 541 companhias listadas na bolsa de valores de Toronto entre 2008 e 2014, e sua correlação entre iniciativas de sustentabilidade e participação feminina. Para isso, adotou-se como proxy para sustentabilidade o disclosure voluntário sobre dados de emissão de gases de efeito estufa. Concluiu-se que quando há mulheres no conselho de administração da empresa, há uma maior divulgação voluntária de dados sobre sustentabilidade, assim como uma maior preocupação com todos os stakeholders.

Gallén e Peraita (2017) investigaram a influência da feminilidade na divulgação de informações de sustentabilidade, com base nas diretrizes da Global Reporting Initiative (GRI), em um contexto de países desenvolvidos. Para tanto, foram utilizadas três medidas da divulgação de informações de RSC por país: os relatórios GRI por milhão de habitantes, os relatórios GRI do nível de aplicação e a porcentagem de relatórios GRI com garantia externa. Os resultados mostram que os países com maior orientação para a feminilidade fornecem maior número de relatórios de sustentabilidade.

Jizi (2017), usando uma amostra de 350 empresas com ações negociadas na bolsa de valores de Londres, no período 2007-2012, examinou como a composição da diretoria e do conselho de administração correlaciona-se com a divulgação social e ambiental da empresa, bem como com a implementação de políticas sociais. Os resultados apontam que uma maior independência do conselho de administração facilita a transmissão da imagem da boa cidadania da empresa através do aumento da consciência social. Os resultados também mostram que a participação das mulheres no conselho de administração afeta favoravelmente o engajamento e os relatórios de sustentabilidade, bem como o estabelecimento de políticas éticas.

Pathak e Pattanayak (2018) examinaram a importância da diversidade de gênero nos conselhos de administração da Índia à luz da recente reforma regulatória introduzida na Lei das Empresas de 2013, que determinava a presença de pelo menos uma mulher nos conselhos de administração de todas as empresas listas em bolsa de valores. Em linhas gerais, os resultados apontam para uma relação positiva entre a presença feminina nos conselhos e o retorno sobre os ativos e uma relação negativa sobre o custo do patrimônio líquido.

Mahmood et al. (2018) buscaram compreender o impacto da governança corporativa nas divulgações de sustentabilidade nas 100 maiores empresas listadas na Bolsa de Valores do Paquistão no período de 2012 a 2015. Os achados do estudo permitiram concluir que um grande conselho de administração, composto por uma diretoria feminina e possuindo um comitê de Responsabilidade Social Empresarial é mais capaz de verificar e controlar as decisões de gestão em relação às questões de sustentabilidade. 
Ítalo Carlos Soares do Nascimento, Adriano Fleck de Paula Pessoa, Alessandra Carvalho de Vasconcelos e Márcia Martins Mendes de Luca

García-Sánchez, Suaréz-Fernández e Martínez-Ferrero (2018) examinaram a relação entre a diversidade do conselho, em termos de diferenças de gênero, e a qualidade do relato de sustentabilidade, medido por vários aspectos: equilíbrio, concisão, clareza, comparabilidade e confiabilidade das informações. Com os achados, os autores evidenciaram que conselhos com maior representatividade feminina diminuem o risco na divulgação da sustentabilidade.

No contexto chinês, Sial et al. (2018) analisaram se a RSC atua como mediadora na relação entre a diversidade de gênero da diretoria e o desempenho da empresa. Os resultados mostram que a diversidade de gênero na diretoria é positivamente correlacionada com o desempenho da empresa, e a RSC media a relação entre a diversidade de gênero da diretoria e o desempenho das empresas chinesas.

Chams e García-Blandón (2019) examinaram a associação entre os determinantes do conselho de administração e o desempenho sustentável. Com base nos índices Dow Jones Sustainability (DJSI) e Standard and Poor's Global Broad Market (S\&P Global BMI), com uma amostra correspondente de 478 empresas multinacionais, os resultados revelam uma relação significativa e positiva entre sustentabilidade e tamanho do conselho, diversidade de gênero, idade média dos conselheiros e número de comitês.

Memon, Akram e Abbas (2020) analisaram o impacto dos diferentes papeis da participação feminina em alcançar a sustentabilidade financeira e o alcance das instituições de micro finanças de 114 países, no período de 1999 a 2017. Os resultados indicam que a participação feminina tem mais impacto no alcance do que na sustentabilidade financeira, trazendo implicações para a formulação de estratégia de mercado-alvo, recrutamento e estratégia de estilo de liderança para o setor de micro finanças para alcançar a redução da pobreza, igualdade de gênero e empoderamento das mulheres.

Destarte, à luz da Teoria dos Stakeholders e com base nas recomendações da literatura, levanta-se a seguinte hipótese: $\left(\mathrm{H}_{1}\right)$ - No Brasil, uma maior participação feminina no conselho de administração é positivamente correlacionada com a sustentabilidade empresarial.

\section{METODOLOGIA}

\subsection{CARACTERIZAÇÃO DA PESQUISA, AMOSTRA E COLETA DE DADOS}

Quanto aos objetivos, trata-se de pesquisa descritiva, por delinear as características de um grupo específico de empresas e por estabelecer correlações entre duas variáveis: participação feminina e sustentabilidade empresarial. Quanto ao problema, caracteriza-se como quantitativa, com abordagem empírico-analítica. No que tange à coleta dos dados, trata-se de pesquisa documental.

A população da pesquisa reúne todas as 444 empresas listadas na B3 em 7 de novembro de 2017. Na seleção da amostra, foram excluídas as empresas do setor financeiro (bancos, companhias de seguros e de investimentos), devido ao fato de suas demonstrações contábeis apresentarem uma estrutura diferenciada em comparação com as das empresas não financeiras, de modo que sua inclusão no grupo sob análise poderia vir a comprometer a validade e a consistência dos resultados. A adoção desse critério se justifica na medida em que o endividamento constitui uma das variáveis de controle do estudo; sendo, portanto, excluído da amostra o setor financeiro, por apresentar características peculiares quanto à estrutura de capital. Após essa exclusão, bem como de empresas que não apresentaram os dados necessários para a pesquisa, a amostra ficou definida em 319 empresas. 
Foram utilizados dados oriundos das Demonstrações Financeiras Padronizadas e do Formulário Referência disponibilizados no website da $\mathrm{B} 3$, além de informações contidas em índices e rankings de sustentabilidade. Os dados referem-se ao exercício social de 2016, tendo sido coletados em novembro de 2017. Inicialmente recorreu-se à análise de conteúdo do Formulário de Referência, de onde se extraíram os dados de participação feminina. Por meio da análise de conteúdo, algumas informações suplementares são fornecidas ao pesquisador, que percorre as fases de pré-análise (seleção do material), exploração do material (documentos), tratamento dos resultados, inferência e interpretação (BARDIN, 2011).

Para atender ao objetivo proposto, a amostra foi distribuída em dois grupos: a) empresas sustentáveis, com base na participação em pelo menos um dos índices de sustentabilidade da B3 (ISE e ICO2) (CARVALHAL; TAVARES, 2013; GUIMARÃES; PEIXOTO; CARVALHO, 2017; LAMEIRA et al., 2013) ou em rankings de sustentabilidade (edições de 2017, com base em informações de 2016) a saber: Guia Exame de Sustentabilidade, Guia Exame Maiores e Melhores Empresas do Brasil, 150 Melhores Empresas Para Trabalhar - Você S/A, Ranking Imprensa - As Empresas Mais Sustentáveis Segundo a Mídia e Ranking Merco Monitor Empresarial de Reputação Corporativa; e b) empresas não sustentáveis. A escolha dos índices e rankings deu-se por distintas perspectivas de análise, cada uma compreendendo pelo menos uma das dimensões de sustentabilidade - ambiental, econômica e social (DAVIES et al., 2003). Destarte, a sustentabilidade de cada empresa é mensurada a partir de sua participação em pelo menos um dos dois índices da bolsa de valores brasileira ou de um dos cinco rankings mencionados, sendo esses os índices e rankings mais utilizados em pesquisas nacionais (CARDOSO; DE LUCA; GALLON, 2014; DOMENICO et al., 2015; LIMA et al., 2015; LOPES et al., 2017). A Tabela 1 expõe a distribuição dos dois grupos considerados na pesquisa, por setor de atuação, de acordo com a classificação setorial da B3.

Tabela 1 - Distribuição da amostra do estudo, por setor de atuação

\begin{tabular}{l|c|c|c}
\multicolumn{1}{c|}{ Setor } & $\begin{array}{c}\text { Grupo 1 } \\
\text { Empresas sustentáveis }\end{array}$ & $\begin{array}{c}\text { Grupo 2 } \\
\text { Empresas não sustentáveis }\end{array}$ & Total \\
\hline Bens industriais & 10 & 57 & 67 \\
\hline Consumo cíclico & 14 & 65 & 79 \\
\hline Consumo não cíclico & 10 & 18 & 28 \\
\hline Materiais básicos & 11 & 19 & 30 \\
\hline Petróleo, gás e biocombustíveis & 2 & 4 & 6 \\
\hline Saúde & 2 & 15 & 17 \\
\hline Tecnologia da informação & 1 & 7 & 8 \\
\hline Telecomunicações & 4 & 2 & 6 \\
\hline Utilidade pública & 18 & 49 & 67 \\
\hline Outros Total & - & 11 & 11 \\
\hline
\end{tabular}

Fonte: dados da pesquisa (2019).

A partir da Tabela 1, observa-se que 72 empresas pertencem ao Grupo 1 - Empresas sustentáveis, enquanto 247 pertencem ao Grupo 2 - Empresas não sustentáveis. Verifica-se também que o setor Utilidade pública reúne 18 empresas no Grupo 1, sendo o segmento com o maior número de empresas sustentáveis, seguido do Consumo cíclico, com 14.

Para a operacionalização das variáveis, a participação feminina é medida pela proporção de representação feminina no conselho de administração - número de mulheres presentes no conselho dividido pelo total de membros (BOULOUTA, 2012; GALBREATH, 2011; GLASS; COOK; INGERSOLL, 2015). Foram ainda incrementadas algumas medidas de controle para neutralizar efeitos que podem impactar a análise. São as variáveis Tamanho (logaritmo 
Ítalo Carlos Soares do Nascimento, Adriano Fleck de Paula Pessoa, Alessandra Carvalho de Vasconcelos e Márcia Martins Mendes de Luca

natural do valor do Ativo) e Endividamento (Exigível / Patrimônio Líquido), obtidos a partir de dados coletados na base Economática ${ }^{\circledR}$; Setor de atuação, Participação no Novo Mercado e Presença de Comitê de Sustentabilidade, obtidos a partir do Formulário de Referência e de Carteiras do Índice de Governança Corporativa (CARDOSO; DE LUCA; GALLON, 2014; CARVALHAL DA SILVA; CHIEN, 2013; GUIMARÃES; PEIXOTO; CARVALHO, 2017; LAMEIRA et al., 2013; LOPES et al., 2017).

\subsection{TRATAMENTO DOS DADOS}

Com o intuito de responder à questão suscitada nesta investigação e de atender aos seus objetivos, os dados foram analisados por meio das seguintes técnicas estatísticas: teste de diferenças entre médias, análise de correspondência múltipla e regressão logística.

Para atingir o objetivo geral, inicialmente utilizou-se a estatística descritiva, com a indicação de valores máximos e mínimos, médias e desvios-padrão. Ressalte-se, também, a utilização do teste de diferenças entre médias de Mann-Whitney, a fim de se verificar a existência de diferenças significativas, estatisticamente, das variáveis utilizadas entre o grupo de empresas sustentáveis e o de empresas não sustentáveis, quanto à participação feminina. Foi utilizado o teste de Mann-Whitney, pois os testes Kolmogorov-Smirnov e Shapiro Wilk apontaram que os dados não apresentavam distribuição normal.

Em seguida, para se verificar quais variáveis indicam maior probabilidade de as empresas serem mais sustentáveis, utilizou-se a regressão logística, que consiste em uma ferramenta de análise multivariada, que tem por objetivo segregar grupos (variável dependente) considerando os efeitos das variáveis independentes na discriminação dos casos observados (MINUSSI; DAMACENA; NESS, 2002). Segundo Dias e Corrar (2009), a regressão logística tem algumas particularidades que a distinguem dos demais modelos de regressão. $A$ principal é a dicotomia que possui a variável dependente, exigindo que o resultado das análises se associe às categorias, como aceitar ou rejeitar, positivo ou negativo. Destaque-se ainda que os resultados da variável dependente devem possibilitar interpretações em termos de probabilidade, e não apenas a classificação em categorias (DIAS; CORRAR, 2009). Assim, foi empregado nesta pesquisa o seguinte modelo (Equação 1):

logit (SUST) $=B_{0}+b_{1} P F+B_{2} T A M+b_{3} E N D+b_{4} S T+b_{5} N M+b_{6} C S+\varepsilon$

Em que:

SUST: Participação em índices ou rankings de sustentabilidade empresarial;

$P F$ : Distribuição da participação feminina;

TAM: Tamanho;

END: Endividamento;

ST: Setor de atuação;

NM: Participação no Novo Mercado;

CS: Presença de Comitê de Sustentabilidade; e

$\varepsilon$ : Termo de Erro.

A variável dependente (sustentabilidade empresarial) é dicotômica (dummy), sendo atribuído o valor " 0 " (zero) para as empresas não sustentáveis - aquelas sem participação em índices e/ou rankings de sustentabilidade - e o valor "1" (um) para as empresas sustentáveis.

A variável independente, constituinte da participação feminina, sua métrica, a fonte de coleta dos dados e a base teórica estão demonstradas no Quadro 1. 
Participação feminina no conselho de administração e a sustentabilidade empresarial

Quadro 1 - Operacionalização da variável independente (participação feminina)

\begin{tabular}{|c|c|c|c|}
\hline Variável & Métrica & Fonte de coleta & Fundamentação \\
\hline $\begin{array}{c}\text { Participação } \\
\text { Feminina }\end{array}$ & $\begin{array}{c}\text { Proporção do número de } \\
\text { mulheres presentes no conselho } \\
\text { dividido pelo número total de } \\
\text { membros }\end{array}$ & $\begin{array}{c}\text { Formulário de } \\
\text { Referência }\end{array}$ & $\begin{array}{c}\text { Boulouta (2012); Galbreath } \\
\text { Glass, Cook e Ingersoll (2015); } \\
\text { Humphries e Whelan (2017); } \\
\text { Silva Júnior e Martins (2017) }\end{array}$ \\
\hline
\end{tabular}

Fonte: elaborado pelos autores (2019).

Para atender ao objetivo adicional de verificar a associação entre participação feminina, sustentabilidade empresarial e governança corporativa, utilizou-se a análise de correspondência múltipla. Segundo Fávero et al. (2009), essa análise exibe as associações entre determinado conjunto de variáveis em um mapa perceptual, no qual se permite o exame da visualização de qualquer padrão nos dados. Para esse objetivo, a variável participação feminina é caracterizada nos seguintes níveis: sem participação, baixa participação, média participação e alta participação. A sustentabilidade empresarial é caracterizada em dois grupos: empresas sustentáveis e empresas não sustentáveis. A governança corporativa, por sua vez, é analisada pelos segmentos de listagem da B3: Mercado Tradicional, Nível 1, Nível 2 e Novo Mercado.

\section{ANÁLISE DOS RESULTADOS}

A Tabela 2 mostra a distribuição quantitativa das empresas por grupo, especificando, para cada grupo, o número de empresas que possuem membro feminino na composição do conselho de administração.

Tabela 2 - Distribuição de empresas por abrangência de membro feminino no conselho

\begin{tabular}{c|c|c|c}
\hline \multirow{2}{*}{ Grupo de empresas } & \multicolumn{3}{|c}{ Participação feminina no conselho de administração } \\
\cline { 2 - 4 } & $\begin{array}{c}\text { No de } \\
\text { empresas }\end{array}$ & $\begin{array}{c}\text { No de empresas com membro } \\
\text { feminino no conselho }\end{array}$ & Proporção (\%) \\
\hline Grupo 1 - Empresas sustentáveis & $\mathbf{7 2}$ & $\mathbf{4 6}$ & 63,9 \\
\hline Grupo 2-Empresas não sustentáveis & 247 & 87 & 35,2 \\
\hline Total & $\mathbf{3 1 9}$ & $\mathbf{1 3 3}$ & - \\
\hline
\end{tabular}

Fonte: dados da pesquisa (2019).

Conforme pode ser observado na Tabela 2, das 319 empresas da amostra, 133 possuem membro feminino no conselho de administração (41,7\%). No Grupo 1 (Empresas sustentáveis), destaca-se que das 72 empresas, 46 possuem membro feminino no conselho, o correspondente a 63,9\%. Com relação às 247 empresas do Grupo 2 (Empresas não sustentáveis), 87 possuem mulheres no conselho de administração, o que corresponde a $35,2 \%$. Dessa forma, os dados revelam que as empresas sustentáveis são as que mais possuem membros femininos no conselho de administração, alinhando-se aos achados da literatura (GALBREATH, 2011; GARCÍA-SÁNCHEZ; SUARÉZ-FERNÁNDEZ; MARTÍNEZ-FERRERO, 2018).

A Tabela 3 apresenta o ranking das empresas sustentáveis com maior participação feminina no conselho de administração, com indicação dos respectivos setores de atuação. 
Ítalo Carlos Soares do Nascimento, Adriano Fleck de Paula Pessoa, Alessandra Carvalho de Vasconcelos e Márcia Martins Mendes de Luca

Tabela 3 - Ranking das empresas sustentáveis com maior participação feminina no conselho de administração

\begin{tabular}{l|c|c|c|c}
\hline \multirow{2}{*}{\multicolumn{1}{c}{ Empresa }} & \multicolumn{2}{|c|}{ Participação feminina no conselho de administração } & \multirow{2}{*}{ Setor de atuação } \\
\cline { 2 - 5 } Magazine Luíza & No de mulheres & Total de membros & Proporção (\%) & Consumo cíclico \\
\hline Copel & 3 & 7 & 42,9 & Utilidade pública \\
\hline Cosern & 3 & 8 & 37,5 & Utilidade pública \\
\hline Coelba & 3 & 9 & 33,3 & Utilidade pública \\
\hline CCR S. A. & 2 & 7 & 28,6 & Bens industriais \\
\hline Lojas Renner & 5 & 20 & 25,0 & Consumo cíclico \\
\hline Duratex & 2 & 8 & 25,0 & Materiais básicos \\
\hline Elektro Redes & 3 & 13 & 23,1 & Utilidade pública \\
\hline Natura & 2 & 9 & 22,2 & Consumo não cíclico \\
\hline Tim & 2 & 9 & 22,2 & Telecomunicações \\
\hline \multicolumn{1}{c}{ Total } & 2 & 9 & 22,2 & - \\
\hline
\end{tabular}

Fonte: dados da pesquisa (2019).

Como mostra a Tabela 3, a Magazine Luíza foi a empresa campeã do ranking, com a maior participação feminina no conselho de administração (42,9\%). Conforme pode ainda ser observado, mesmo considerando-se as empresas com as maiores participações, a maioria delas apresenta entre duas e três mulheres no conselho. Esse resultado vai de encontro ao estudo de Boulouta (2012), que ao examinar como um conselho de administração com mulheres afeta a performance social da empresa com ações negociadas na bolsa de Nova lorque, considerou na composição da amostra as empresas com pelo menos três mulheres no conselho. Entretanto, segundo a autora, com essa condição a amostra ficou pouco representativa e limitada, impedindo a realização da análise; portanto, diante dessa limitação, a análise contemplou todas as empresas com pelo menos uma mulher no conselho de administração.

Cabe destacar também que a Copel, a Cosern e a Coelba - segunda, terceira e quarta colocadas, respectivamente - pertencem ao setor Utilidade Pública, além da Elektro Redes (oitava colocada), também atuante nesse segmento. Destarte, o setor Utilidade Pública foi o que apresentou o maior número de empresas sustentáveis com maior participação feminina no conselho de administração, corroborando achados anteriores, tais como o estudo de Tonolli, Rover e Ferreira (2017) ao concluírem que o setor utilidade pública é o mais representativo das empresas participantes do ISE, seguido do setor financeiro e Lima et al. (2015) ao identificarem que o setor utilidade pública é o mais sustentável. Uma das possíveis explicações é a obrigatoriedade deste setor no que tange à divulgação de suas informações de natureza socioambiental, tendo em vista que desde 1998 a Agência Nacional de Energia Elétrica (ANEEL), recomenda que estas organizações publiquem a Demonstração do Valor Adicionado e o Balanço Social, tornando esta publicação obrigatória a partir de 2003 para as empresas deste setor.

Na sequência, foi realizado o teste Qui-Quadrado, para se analisar a associação entre as variáveis participação feminina, sustentabilidade empresarial e governança corporativa (objetivo adicional), com o intuito de atestar a viabilidade da aplicação e execução da Análise Múltipla de Correspondência (ACM). A Tabela 4 apresenta os resultados do teste Quiquadrado realizado para cada análise de correspondência. 
Participação feminina no conselho de administração e a sustentabilidade empresarial

Tabela 4 - Teste Qui-quadrado

\begin{tabular}{l|c|c}
\hline \multirow{2}{*}{ Correspondência } & \multicolumn{2}{c}{ Teste Qui-Quadrado } \\
\cline { 2 - 3 } Participação Feminina X Sustentabilidade Empresarial & 30,185 & $0,000\left(^{*}\right)$ \\
\hline Participação Feminina X Governança Corporativa & 28,888 & $0,001\left(^{*}\right)$ \\
\hline
\end{tabular}

Nota: $\left.{ }^{*}\right)$ Significante a $1 \%$.

Fonte: dados da pesquisa (2019).

Nota-se, a partir da Tabela 4, que os resultados indicam significância estatística a um nível inferior a $1 \%$. Observada a significância dos resultados, analisa-se a associação entre participação feminina, sustentabilidade empresarial e governança corporativa, a partir do mapa perceptual (Figura 1).

No mapa da Figura 1, verifica-se que as empresas sem participação feminina no conselho de administração estão associadas ao grupo daquelas não sustentáveis e não listadas em nenhum segmento diferenciado de governança da B3. Destaque-se também que as empresas com baixa participação feminina estão associadas ao grupo das sustentáveis e ao segmento Nível 2 da B3. Por sua vez, as empresas com média participação estão associadas ao segmento Novo Mercado da B3, porém sem demonstrar proximidade com os grupos de empresas sustentáveis e não sustentáveis. Por fim, as empresas com alta participação não apontaram associação com nenhum dos grupos empresariais considerados, nem com os segmentos de governança corporativa.

Figura 1 - Mapa perceptual da associação entre participação feminina, sustentabilidade empresarial e governança corporativa

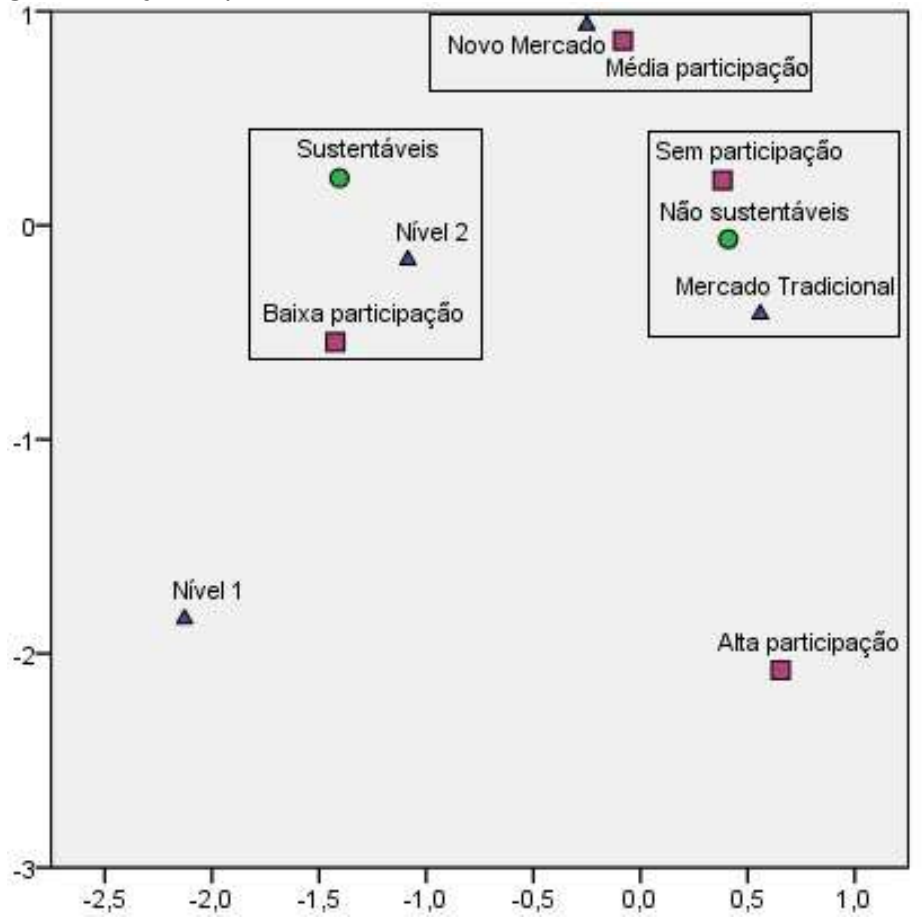

$\Delta$ Govemança Corporativa
Participação Feminina

O Participação Feminuma

Fonte: dados da pesquisa (2019).

Em linhas gerais, os dados sugerem uma associação positiva entre participação feminina, sustentabilidade empresarial e governança corporativa. A baixa participação feminina é explicada por estudos empíricos, como os de Boulouta (2012), Gallén e Peraita (2017), Jizi (2017) e Viviers, Mans-Kemp e Fawceet (2017), que também constataram uma baixa representatividade feminina nos conselhos. Por outro lado, nota-se que as empresas não sustentáveis são as que não possuem participação feminina, nem são listadas nos níveis 
Ítalo Carlos Soares do Nascimento, Adriano Fleck de Paula Pessoa, Alessandra Carvalho de Vasconcelos e Márcia Martins Mendes de Luca

diferenciados de governança corporativa. Com isso, pode-se considerar que a adoção de melhores práticas de governança corporativa contribui para o bem-estar de todos os stakeholders envolvidos com a empresa (GÓIS et al., 2017), e, por conseguinte, converge para uma maior preocupação com as políticas de sustentabilidade da organização, conforme sinalizado por alguns autores estrangeiros (DYLLICK; HOCKERTS, 2002; LINNENLUECKE; GRIFFITHS, 2010).

Para o alcance do objetivo geral, primeiramente procedeu-se à estatística descritiva das variáveis, por grupo empresarial (Tabela 5), com exceção do setor de atuação (ST), participação no Novo Mercado (NM) e presença de comitê de sustentabilidade (CS), que são variáveis dummy na regressão logística.

Tabela 5 - Estatística descritiva das variáveis

\begin{tabular}{c|l|c|c|c|c|c}
\hline \multicolumn{2}{c|}{ Variável } & Média & $\begin{array}{c}\text { Desvio- } \\
\text { padrão }\end{array}$ & Mínimo & Máximo & $\begin{array}{c}\text { Coeficiente } \\
\text { de Variação }\end{array}$ \\
\hline $\begin{array}{c}\text { Participação } \\
\text { Feminina }\end{array}$ & Sustentáveis & 0,1031 & 0,1035 & 0,0000 & 0,4286 & 0,011 \\
\hline \multirow{2}{*}{ Tamanho } & Não Sustentáveis & 0,0857 & 0,1511 & 0,0000 & 1,0000 & 0,023 \\
\hline \multirow{2}{*}{ Endividamento } & Sustentáveis & 20,9664 & 4,0665 & 9,8702 & 27,4140 & 16,537 \\
& Não Sustentáveis & 15,2372 & 3,8041 & 7,0951 & 24,3273 & 14,472 \\
\hline
\end{tabular}

Fonte: dados da pesquisa (2019).

$\mathrm{Na}$ Tabela 5, verifica-se uma maior presença feminina no conselho no grupo de empresas sustentáveis (10,3\%). Já a participação feminina nas empresas não sustentáveis foi de $8,6 \%$. Observa-se a presença de maior tamanho entre as empresas sustentáveis (Grupo 1). Quanto à estrutura de capital, nota-se maior endividamento entre as empresas não sustentáveis. Com isso, constata-se que, no geral, as empresas sustentáveis são maiores e menos endividadas.

Verifica-se também que para a variável participação feminina, a dispersão de dados, indicada pelo desvio-padrão e pelo coeficiente de variação, é menor nas empresas sustentáveis do que nas não sustentáveis, indicando que a variação da participação de membros femininos no conselho de administração é menor nesse grupo de empresas. Ressalte-se que das 72 empresas sustentáveis, apenas 25 não possuem membro feminino, 25 possuem um membro, 10 possuem dois membros e 9 possuem três mulheres no conselho, sendo esses os valores mais expressivos. Esse achado corrobora os resultados encontrados em outros países, segundo os quais as companhias sustentáveis possuem, em média, entre uma e três mulheres no conselho de administração (BOULOUTA, 2012; GALBREATH, 2011; GLASS; COOK; INGERSOLL, 2015).

Cabe salientar que o valor máximo da variável participação feminina, de $100 \%$, foi observado no grupo de empresas não sustentáveis, mais especificamente na Nordon Indústrias Metalúrgicas S. A., que possui um único membro em seu conselho, sendo este, por sua vez, do gênero feminino. Das 247 empresas não sustentáveis, 158 não apresentam membro feminino, 52 possuem apenas um e 25 possuem dois em seu conselho, sendo esses os números mais expressivos. Destarte, constata-se que no contexto geral das companhias brasileiras de capital aberto, o grupo de empresas sustentáveis é o que apresenta o maior número de mulheres no conselho de administração.

Para analisar diferenças significativas entre as variáveis das empresas sustentáveis e as das não sustentáveis, aplicou-se o teste entre médias para amostras independentes de Mann-Whitney (Tabela 6). Através dos testes de Kolmogorov-Smirnov e Shapiro-Wilk, certificou-se que quase nenhuma das variáveis apresentou distribuição normal, já que o p- 
valor dos testes foi inferior a 0,05, justificando-se, assim, a utilização do teste não paramétrico.

Tabela 6 - Teste não paramétrico de Mann-Whitney

\begin{tabular}{l|c|c|c|c|c}
\hline Participação Feminina & $\begin{array}{c}\text { No de } \\
\text { empresas }\end{array}$ & $\begin{array}{c}\text { Mann- } \\
\text { Whitney }\end{array}$ & Wilcoxon W & Z & $\begin{array}{c}\text { Asymp. Sig. } \\
\text { (2-tailed) }\end{array}$ \\
\hline $\begin{array}{l}\text { Grupo 1 - Empresas Sustentáveis } \\
\text { Grupo 2 - Empresas Não Sustentáveis }\end{array}$ & $\begin{array}{c}72 \\
247\end{array}$ & $6.940,5$ & $37.568,5$ & $-3,147$ & $0,002(*)$ \\
\hline
\end{tabular}

Nota: (*) Significante a $1 \%$.

Fonte: dados da pesquisa (2019).

Com base nos resultados exibidos na Tabela 6, nota-se que há diferenças significativas entre as empresas sustentáveis e as não sustentáveis quanto à variável participação feminina. Ou seja, os resultados sugerem que nas empresas sustentáveis ocorre uma maior participação feminina no conselho de administração. Esse resultado corrobora os achados da literatura estrangeira, os quais apontam para uma correlação positiva entre uma maior participação feminina no conselho e melhores práticas e/ou políticas de sustentabilidade empresarial (BOULOUTA, 2012; GALBREATH, 2011; GALLÉN; PERAITA, 2017; GLASS; COOK, 2018; JIZI, 2017; MAHMOOD et al., 2018; SIAL et al., 2018).

Desse modo, foi delineada a regressão logística, com o intuito de se comprovar a hipótese geral de que, no Brasil, uma maior participação feminina no conselho de administração é positivamente correlacionada com a maior sustentabilidade empresarial. $\mathrm{Na}$ Tabela 7, dispõem-se os resultados da regressão, provenientes da Equação 1.

Tabela 7 - Regressão logística - sustentabilidade empresarial

\begin{tabular}{l|c|c|c|c}
\hline \multirow{2}{*}{ Variável } & LR Qui $^{\mathbf{2}}$ & Pseudo R & Sig. & N \\
\cline { 2 - 5 } & 124,43 & 0,3652 & $0,00\left(^{*}\right)$ & 319 \\
\cline { 2 - 5 } & Coef. & Erro-padrão & $\mathbf{Z}$ & Sig. \\
\hline Participação Feminina & 0,9677 & 0,3484 & 2,78 & $0,005\left(^{*}\right)$ \\
\hline Tamanho & 0,2950 & 0,0428 & 6,88 & 0,000 \\
\hline Endividamento & 0,0007 & 0,1157 & 0,65 & 0,517 \\
\hline Novo Mercado & $-0,1045$ & 0,3631 & $-0,29$ & 0,773 \\
\hline Setor de Atuação & $-0,2921$ & 0,3828 & $-0,76$ & 0,445 \\
\hline Comitê de Sustentabilidade & 2,4875 & 0,5827 & 4,27 & 0,000 \\
\hline Constante & $-7,1599$ & 0,8480 & $-8,44$ & 0,000 \\
\hline
\end{tabular}

Nota: $\left.{ }^{*}\right)$ Significante a $1 \%$.

Fonte: dados da pesquisa (2019).

Ainda na Tabela 7, verifica-se que o poder explicativo, baseado no Pseudo $\mathrm{R}^{2}$ do modelo 1 , é considerado baixo, e que o modelo é significante ao nível de $1 \%$. Desse modo, o modelo é válido, possibilitando a inferência de resultados.

Observa-se que a participação feminina, o tamanho e a presença de comitê de sustentabilidade são as variáveis com maior probabilidade de exercer correlação com a sustentabilidade empresarial, indicada pela significância ao nível de $1 \%$. Destarte, quanto maior o número de mulheres no conselho de administração da empresa, maior a sua probabilidade de ser sustentável, já que a variável participação feminina apresentou correlação positiva com a variável sustentabilidade empresarial. Destaque-se também que, quanto maior o tamanho da empresa, maior a sua probabilidade de ser sustentável, devido à identificação de correlação positiva entre o tamanho e a sustentabilidade empresarial. Por sua vez, a presença de comitê de sustentabilidade também indica maior probabilidade de a empresa ser sustentável, já que foi encontrada uma correlação positiva entre as variáveis comitê de sustentabilidade e sustentabilidade empresarial. 
Ítalo Carlos Soares do Nascimento, Adriano Fleck de Paula Pessoa, Alessandra Carvalho de Vasconcelos e Márcia Martins Mendes de Luca

Esse resultado é corroborado por diversos estudos, incluindo os de Bem-Amar et al. (2015), Boulouta (2012), Galbreath (2011), Gallén e Peraita (2017), Glass e Cook (2018), Jizi (2017), Mahmood et al. (2018) e Sial et al. (2018), os quais indicam uma correlação positiva entre participação feminina na composição do conselho de administração e adoção de políticas de sustentabilidade. Vale ressaltar que os citados autores também utilizaram a variável de controle tamanho, mensurada pelo logaritmo natural do valor do Ativo, confirmada como positiva nesta pesquisa. Já a correlação positiva entre a presença de comitê de sustentabilidade e a sustentabilidade empresarial foi igualmente evidenciada em estudos anteriores, como, por exemplo, os de Bomfim, Teixeita e Monte (2015) e Michelon e Parbonetti (2012). Cabe destacar que, pela ótica da Teoria dos Stakeholders, as mulheres têm uma maior preocupação com os interesses dos stakeholders, e não apenas com os dos shareholders, diferentemente dos homens, que focam mais em seus próprios interesses (BIGGINS, 1999; GROSSER; MOON, 2005).

Ressalte-se ainda que a maioria dos estudos anteriores que constataram a relação entre a participação feminina no conselho e a sustentabilidade empresarial utilizaram a Teoria dos Stakeholders como sustentação teórica, tais como Galbreath (2011) e Memon, Akram e Abbas (2020). Sob a ótica da referida teoria, os gestores formulam e implementam suas estratégias visando à satisfação de seus stakeholders, em vez de maximizarem os direitos de um único grupo em detrimento dos demais. Portanto, as mulheres integrantes de conselho de administração exercem maior impacto na governança corporativa da organização, já que apresentam melhor empenho e diferentes percepções em comparação com os homens, notadamente por possuírem sentimento altruístico e senso de coletividade (ADAMS; FERREIRA, 2009; GLASS; COOK, 2018; NISIYAMA; NAKAMURA, 2018; PLETZER et al., 2015; YAP, 2017), representando melhor as necessidades de todos os stakeholders (BIGGINS, 1999), confirmando, portanto, os prognósticos da Teoria dos Stakeholders.

Pode-se afirmar, por conseguinte, que as empresas listadas na B3 com maior participação feminina no conselho de administração revelam maior probabilidade para a sustentabilidade empresarial, considerando-se a amostra e o exercício em análise. Dessa forma, os resultados obtidos no presente estudo aceitam a hipótese geral de que, no Brasil, uma maior participação feminina no conselho de administração é positivamente correlacionada com a sustentabilidade empresarial.

\section{CONSIDERAÇÕES FINAIS}

Por ser o principal órgão de governança corporativa, o conselho de administração desempenha papel fundamental no direcionamento e monitoramento das políticas organizacionais. Conforme mencionado, ao longo das últimas décadas, a sociedade passou a demandar mais atenção no tratamento da sustentabilidade empresarial por parte das organizações. Alguns estudos mostraram a influência que a diversidade - de independência, gênero e nacionalidade - na composição do conselho exerce em questões como performance, e até mesmo na questão socioambiental. Com base na Teoria dos Stakeholders, analisou-se a correlação entre a participação feminina no conselho de administração e a sustentabilidade empresarial em 319 companhias listadas na B3.

Por meio da análise descritiva, verificou-se que as empresas sustentáveis - as que participam de índices ou rankings de sustentabilidade - são as que possuem mais mulheres no conselho de administração. Entretanto, os resultados revelam que a participação feminina nas empresas da amostra é baixa, corroborando achados empíricos de estudiosos 
Participação feminina no conselho de administração e a sustentabilidade empresarial

estrangeiros. Ainda por meio da análise descritiva, notou-se as empresas dos setores Utilidade Pública e Consumo Cíclico são as que possuem mais mulheres no conselho.

Em linhas gerais, os resultados da análise de correspondência múltipla confirmaram a associação positiva entre participação feminina, sustentabilidade empresarial e governança corporativa. Assim, afirma-se que a adoção de melhores práticas de governança contribui para o bem-estar dos stakeholders envolvidos com a organização, e, por conseguinte, converge para uma maior preocupação com as políticas de sustentabilidade empresarial.

O teste de diferenças entre médias revelou que há diferenças significativas entre as empresas sustentáveis e as não sustentáveis no que tange à variável participação feminina, o que foi ratificado mediante aplicação da regressão logística. Destaque-se que a participação feminina, o tamanho e a presença de comitê de sustentabilidade são as variáveis com mais probabilidade de exercer essa correlação. Dessa forma, os resultados aceitam a hipótese geral, haja vista que trazem implicações para a compreensão da participação feminina na alta gestão organizacional e para a sustentabilidade empresarial no mercado de capitais brasileiro.

Entende-se que o estudo da diversidade do conselho de administração e da sustentabilidade empresarial proporciona reflexões sobre a busca pelo valor a longo prazo, permitindo assim visualizar a Teoria dos Stakeholders, a qual sustenta que as empresas, para garantir valor a longo prazo, necessitam conciliar os interesses dos diversos stakeholders. Ressalte-se, portanto, a importância da sustentabilidade empresarial como estratégia para a melhoria da imagem e reputação das empresas, captação vantajosa de recursos e maior vantagem competitiva.

Além disso, ressalte-se a importância da diversidade do conselho de administração representada neste estudo especialmente pela participação feminina -, como recurso estratégico, contribuindo para o crescimento, competitividade e longevidade dos negócios, haja vista os benefícios proporcionados através da participação feminina em cargos de alta gestão, observada tanto nesta pesquisa, no contexto brasileiro (país em desenvolvimento), como também em países desenvolvidos, notadamente percebida em estudos estrangeiros. Destarte, pela ótica da Teoria dos Stakeholders, esta pesquisa, especialmente para o caso das empresas brasileiras, sinaliza que as mulheres têm uma maior preocupação com os interesses de todos os stakeholders, e não apenas com os dos shareholders, diferentemente dos homens, que focam mais em seus próprios interesses, seguindo as recomendações da literatura estrangeira.

Ressalte-se que a correlação entre os dois construtos - participação feminina e sustentabilidade empresarial - foi vista tanto sob o enfoque teórico quanto sob o empírico, na medida em que, ao se confrontar as empresas sustentáveis com as não sustentáveis, identificaram-se diferenças significantes no tocante à participação feminina, revelando-se assim que as sustentáveis têm maior probabilidade de incluir membro feminino no conselho.

Verifica-se uma escassez de estudos nacionais acerca dessa temática, e as pesquisas encontradas são incipientes, havendo, portanto, a necessidade de maior aprofundamento no assunto. A pesquisa avança nos campos teórico e prático, porém algumas limitações podem ser apontadas, razão pela qual sugere-se uma reflexão para futuras pesquisas, tanto quanto à influência de uma maior participação feminina nos conselhos, como em relação às práticas sustentáveis e de governança corporativa, em especial quanto ao uso de outras medidas e ampliação de variáveis. Apesar da dificuldade de se obter métricas que refletissem a contrapartida socioambiental, conseguiu-se, por meio da participação em índices e rankings de sustentabilidade, um grupo de 72 empresas sustentáveis dentre as 319 da amostra. 
Ítalo Carlos Soares do Nascimento, Adriano Fleck de Paula Pessoa, Alessandra Carvalho de Vasconcelos e Márcia Martins Mendes de Luca

O presente estudo cobre apenas um período, podendo ser replicado em um lapso temporal maior, suscitando inferência acerca do efeito temporal dos dados. Destaque-se, ainda, a possibilidade de análise comparativa entre empresas de países em desenvolvimento e empresas de nações desenvolvidas.

\section{REFERÊNCIAS}

ACKERMAN, R. W. The social challenge to business. Cambridge, MA: Harvard University Press, 1975.

ADAMS, B. R.; FERREIRA, D. Women in the boardroom and their impact on governance and performance. Journal of Financial Economics, Amsterdam, v. 94, n. 1, p. 291-309, 2009. DOI: https://doi.org/10.1016/j.jfineco.2008.10.007.

ADAMS, B. R.; HERMALIN, B.; WEISBACH, M. The role of boards of directors in corporate governance: a conceptual framework and survey. Journal of Economic Literature, United States, v. 48, n. 1, p. 58-107, 2010. DOI: https://doi.org/10.1257/jel.48.1.58.

ANCA, C.; GABALDON, P. The media impact of board member appointments in Spanish-listed companies: A gender perspective. Journal of Business Ethics, Berlin, v. 122, n. 3, p. 425-438, 2014. DOI: https://doi.org/10.1007/s10551-013-1768-1.

ARAYSSI, M.; DAH, M.; JIZI, M. Women on boards, sustainability reporting and firm performances. Accounting, Management and Policy Journal, Bingley, v. 7, n. 3, p. 376-401, 2016. DOI: https://doi.org/10.1108/SAMPJ-07-2015-0055.

B3 S. A. - Brasil, Bolsa, Balcão. Índice de carbono eficiente (ICO2). Disponível em: http://www.bmfbovespa.com.br/pt_br/produtos/indices/indices-desustentabilidade/indice-carbono-eficiente-ico2.htm. Acesso em: 20 nov. 2017.

BARDIN, L. Análise de conteúdo. Lisboa: Edições 70, 2011.

BEN-AMAR, W.; CHANG, M.; MCILKENNY, P. Board gender diversity and corporate response to sustainability initiatives: Evidence from the carbon disclosure project. Journal of Business Ethics, Berlin, v. 142, n. 2, p. 369-383, 2017. DOI: https://doi.org/10.1007/s10551-015-27591.

BIGGINS, J. V. Making board diversity work. Corporate Board, New Jersey, v. 20, n. 117, p. 11-17, 1999.

BOMFIM, E. T. D.; TEIXEIRA, W. D. S.; MONTE, P. A. D. Relação entre o disclosure da sustentabilidade com a governança corporativa: Um estudo nas empresas listadas no IBRX100. Sociedade, Contabilidade e Gestão, Rio de Janeiro, v. 10, n. 1, p. 6-28, 2015. DOI: https://doi.org/10.21446/scg_ufrj.v10i1.13341.

BORBA, M. A.; SANTOS, M. D.; DAGOSTINI, L.; SCHVIRCK, E. A influência das características do conselho de administração, comitê de ética e conselho fiscal no audit delay. RGO -

Revista Gestão Organizacional, Chapecó, v. 12, n. 3, p. 158-175, Edição Especial, 2019. 
DOI: https://doi.org/10.22277/rgo.v12i3.5203.

BOULOUTA, I. Hidden connections: The link between board gender diversity and corporate social performance. Journal of Business Ethics, Berlin, v. 113, n. 2, p. 185-197, 2012. DOI: https://doi.org/10.1007/s10551-012-1293-7.

BYRON, K.; POST, C. Women on boards of directors and corporate social performance: A meta-analysis. Corporate Governance: An International Review, New Jersey, v. 24. n. 4, p. 428-442, 2016. DOI: https://doi.org/10.1111/corg.12165.

CAPPELLE, M. C. A.; BRITO, M. J. M.; MELO, M. C. O. L.; BRITO, M. J. Uma análise da dinâmica do poder e das relações de gênero no espaço organizacional. Revista de Administração de Empresas Eletrônica, São Paulo, v. 3, n. 2, p. 1-17, 2004.

CARDOSO, V. I. C.; DE LUCA, M. M. M.; GALLON, A. V. Reputação corporativa e o disclosure socioambiental de empresas brasileiras. Contabilidade, Gestão e Governança, Brasília, v. 17, n. 2, p. 26-44, 2014.

CARRASCO, A.; FRANCOEUR, C.; LABELLE, R.; LAFFARGA, J.; RUIZ-BARBADILLO, E. Appointing women to boards: Is there a cultural bias? Journal of Business Ethics, Berlin, v. 129, n. 2, p. 429-444, 2015. DOI: https://doi.org/10.1007/s10551-014-2166-z.

CARVALHAL, A.; TAVARES, E. Does social responsability enhance firm value and return in Brazil? Corporate Ownership \& Control, Gagarina, v. 10, n. 2, p. 253-258, 2013. DOI: https://doi.org/10.22495/cocv10i2c2art4.

CARVALHAL DA SILVA, A. L.; CHIEN, A. C. Y. Remuneração executiva, valor e desempenho das empresas brasileiras listadas. Revista Brasileira de Finanças, São Paulo, v. 11, n. 4, p. 481502, 2013.

CHAMS, N.; GARCÍA-BLANDÓN, J. Sustainable or not sustainable? The role of the board of directors. Journal of cleaner production, Amsterdam, v. 226, n. 2, p. 1067-1081, 2019. DOI: https://doi.org/10.1016/j.jclepro.2019.04.118.

CLARKSON, M. B. E. A stakeholder framework for analyzing and evaluating corporate social performance. The Academy of Management Review, United States, v. 20, n. 1, p. 92-117, 1995. DOI: https://doi.org/10.2307/258888.

COIMBRA, F.C. Estrutura de governança corporativa e gestão de riscos: um estudo de caso no setor financeiro. 2011. Tese (Doutorado). Universidade de São Paulo, 2011.

DAVIES, G.; CHUN, R.; DA SILVA, R. V.; ROPER, S. Corporate reputation and competitiveness. Corporate Communications: An International Journal, Bingley, v. 8, n. 2, p. 48-149, 2003. DOI: https://doi.org/10.1108/ccij.2003.8.2.148.1.

DE LUCA, M. M. M.; CARDOSO, V. I. C.; VASCONCELOS, A. C.; PONTES, A. C. Análise da produção científica referente à temática de sustentabilidade em pesquisas da 
Ítalo Carlos Soares do Nascimento, Adriano Fleck de Paula Pessoa, Alessandra Carvalho de Vasconcelos e Márcia Martins Mendes de Luca

Administração. Administração: Ensino e Pesquisa, Rio de Janeiro, v. 15, n. 3, p. 469-500, 2014. DOI: https://doi.org/10.13058/raep.2014.v15n3.10.

DIAS FILHO, J. M.; CORRAR, L. J. Regressão logística. In: CORRAR, L. J.; PAULO, E.; DIAS FILHO, J. M. (Org.). Análise multivariada: Para os cursos de administração, ciências contábeis e economia. São Paulo: Atlas, 2009.

DOMENICO, D. D.; MAZZIONI, S.; DAL MAGRO, C. B.; PERUZZO, M.; PERUZZO, M. Análise dos indicadores ambientais das empresas listadas no Guia de Sustentabilidade da Revista Exame. Ciências Sociais Aplicadas em Revista, Cascavel, v. 15, n. 28, p. 65-89, 2015.

DONALDSON, T.; PRESTON, L. E. The stakeholder theory of the corporation: concepts, evidence and implications. Academy of Management Review, United States, v. 20, n. 1, p. 65-91, 1995. DOI: https://doi.org/10.2307/258887.

DYLLICK, T.; HOCKERTS, K. Beyond the business case for corporate sustainability. Business Strategy and the Environment, New Jersey, v. 11, n. 2, p. 130-141, 2002. DOI: https://doi.org/10.1002/bse.323.

ECCLES, R.; SALTZMAN, D. Achieving sustainability through integrated reporting. Stanford Social Innovation Review, California, v. 9, n. 3, p. 56-61, 2011.

ELKINGTON, J. Canibais com garfo e faca. São Paulo: Makron Books, 2001.

FAMA, E. F.; JENSEN, M. C. Agency problems and residual claims. Journal of Law and Economics, Chicago, v. 26, n. 2, p. 327-350, 1983.

FÁVERO, L. P. L.; BELFIORE, P.; SILVA, F. L.; CHAN, B. Análise de dados: Modelagem multivariada para tomada de decisões. São Paulo: Campus, 2009.

FERNANDEZ-FEIJOO, B.; ROMERO, S.; RUIZ-BLANCO, S. Women on boards: Do they affect sustainability reporting? Corporate Social Responsibility and Environmental Management, New Jersey, v. 21, n. 6, p. 351-364, 2014. DOI: https://doi.org/10.1002/csr.1329.

FERREIRA, R. N. Responsabilidade social, governança corporativa e valor das empresas. Revista de Administração da UFLA, Lavras, v. 6, n. 1, p. 132-141, 2004.

FERRERO-FERRERO, I.; FERNÁNDEZ-IZQUIERDO, M. Á.; MUÑOZ-TORRES, M. J. Integrating sustainability into corporate governance: An empirical study on board diversity. Corporate Social Responsibility and Environmental Management, New Jersey, v. 22, n. 4, p. 193-207, 2015. DOI: https://doi.org/10.1002/csr.1333.

FONSECA, C. V. C.; SILVEIRA, R. L. F. Governança corporativa e custo de capital de terceiros: evidências entre empresas brasileiras de capital aberto. REAd - Revista Eletrônica de Administração, Porto Alegre, v. 83, n. 1, p. 106-133, 2016. DOI: http://dx.doi.org/10.1590/1413-2311.016162016.62739. 
FRANCO, I. T.; TEIXEIRA, M. G.; AZEVEDO, D. B.; MOURA-LEITE, R. C. A inserção da temática de sustentabilidade na formação de futuros gestores: Como os professores se deparam com o assunto? Administração: Ensino e Pesquisa, Rio de Janeiro, v. 16, n. 3, p. 571-607, 2015. DOI: https://doi.org/10.13058/raep.2015.v16n3.284.

FREEMAN, R. E.; MCVEA, J. A stakeholder approach to strategic management. The Blackwell Handbook of Strategic Management, Virginia, p. 183-201, 2001. DOI:

https://doi.org/10.2139/ssrn.263511.

FURLAN, F. O sinal que vem das ruas. (Guia Exame de Sustentabilidade 2013). São Paulo: Editora Abril, 2013.

GALBREATH, J. Are there gender-related influences on corporate sustainability? A study of women on boards of directors. Journal of Management \& Organization, Cambridge, v. 17, n. 1, p. 17-38, 2011. DOI: https://doi.org/10.5172/jmo.2011.17.1.17.

GALLÉN, M. L.; PERAITA, C. The relationship between femininity and sustainability reporting. Corporate Social Responsibility and Environmental Management, New Jersey, v. 24, n. 1, p. 496-508, 2017. DOI: https://doi.org/10.1002/csr.1423.

GARCÍA-SÁNCHEZ, I.; SUÁREZ-FERNÁNDEZ, O.; MARTÍNEZ-FERRERO, J. Female directors and impression management in sustainability reporting. International Business Review,

Amsterdam, v. 28, n. 2, p. 359-374, 2018. DOI:

https://doi.org/10.1016/j.ibusrev.2018.10.007.

GILLIGAN, C. In a different voice. Cambridge, MA: Harvard University Press, 1982.

GLASS, C.; COOK, A.; INGERSOLL, A. R. Do women leaders promote sustainability? Analyzing the effect of corporate governance composition on environmental performance. Business Strategy and the Environment, New Jersey, v. 25, n. 7, p. 495-511, 2015. DOI: https://doi.org/10.1002/bse.1879.

GLASS, C.; COOK, A. Do women leaders promote positive change? Analyzing the effect of gender on business practices and diversity initiatives. Human Resource Management, New Jersey, v. 57, n. 4, p. 823-837, 2018. DOI: https://doi.org/10.1002/hrm.21838.

GÓIS, A. D.; DE LUCA, M. M. M.; LIMA, G. A. S. F.; VASCONCELOS, A. C. Reputação gera valor para os acionistas? Uma análise nas empresas brasileiras. Revista de Administração, Contabilidade e Economia, Joaçaba, v. 16, n. 2, p. 523-546, 2017. DOI: https://doi.org/10.18593/race.v16i2.13048.

GROSSER, K.; MOON, J. Gender mainstreaming and corporate social responsibility: Reporting workplace issues. Journal of Business Ethics, Berlin, v. 62, n. 4, 327-340, 2005. DOI: https://doi.org/10.1007/s10551-005-5334-3.

GUAY, T.; DOH, J. P.; SINCLAIR, G. Non-governmental organizations, shareholder activism, and socially responsible investments: Ethical, strategic, and governance implications. Journal 
Ítalo Carlos Soares do Nascimento, Adriano Fleck de Paula Pessoa, Alessandra Carvalho de Vasconcelos e Márcia Martins Mendes de Luca

of Business Ethics, Berlin, v. 52, n. 1, p. 125-139, 2004. DOI:

https://doi.org/10.1023/B:BUSI.0000033112.11461.69.

GUIMARÃES, T. M.; PEIXOTO, F. M.; CARVALHO, L. Sustentabilidade empresarial e governança corporativa: Uma análise da relação do ISE da BM\&FBovespa com a compensação dos gestores de empresas brasileiras. Revista de Educação e Pesquisa em Contabilidade, Brasília, v. 11, n. 2, p. 134-149, 2017. DOI:

https://doi.org/10.17524/repec.v11i2.1418.

HARO-DE-ROSARIO, A.; GÁLVEZ-RODRÍGUEZ, M. D. M.; SÁEZ-MARTíN, A.; CABA-PÉREZ, C. El rol del consejo de administración en la ética empresarial en países de Latinoamérica. Revista de Administração de Empresas, São Paulo, v. 57, n. 5, p. 426-438, 2017. DOI:

http://dx.doi.org/10.1590/s0034-759020170502.

HENDRY, K.; KIEL, G. C. The role of the board in firm strategy: Integrating agency and organizational control perspectives. Corporate Governance: An International Review, New Jersey, v. 12, n. 4, p. 500-520, 2004. DOI: https://doi.org/10.1111/j.1467-

8683.2004.00390.x.

HUMPHRIES, S. A.; WHELAN, C. National culture and corporate governance codes. Corporate Governance: The International Journal of Business in Society, Bingley, v. 17, n. 1, p. $152-$ 163, 2017. DOI: https://doi.org/10.1108/CG-06-2016-0127.

HUSSAIN, N.; RIGONI, U.; ORIJ, R. P. Corporate governance and sustainability performance: Analysis of triple bottom line performance. Journal of Business Ethics, Berlin, v. 149, n. 2, p. 411-432, 2018. DOI: https://doi.org/10.1007/s10551-016-3099-5.

INSTITUTO BRASILEIRO DE GOVERNANÇA CORPORATIVA. Código das melhores práticas de governança corporativa. 5. ed. São Paulo: IBGC, 2015.

JENSEN, M. C. Value maximization, stakeholder theory, and the corporate objective function. Business Ethics Quarterly, Cambridge v. 12, n. 2 p. 235-256, 2002. DOI: https://doi.org/10.2307/3857812.

JIZI, M. The influence of board composition on sustainable development disclosure. Business Strategy and the Environment, New Jersey, v. 26, n. 1, p. 640-655, 2017. DOI: https://doi.org/10.1002/bse.1943.

JOHN, K.; SENBET, L. W. Corporate governance and board effectiveness. Journal of Banking \& Finance, Amsterdam, v. 22, p. 371-403, 1998. DOI: https://doi.org/10.1016/S03784266(98)00005-3.

JOHNSON, R.; GREENING, D. The effects of corporate governance and institutional ownership types on corporate social performance. The Academy of Management Journal, United States, v. 42, n. 5, p. 564-576, 1999. DOI: https://doi.org/10.2307/256977. 
KAKABADSE, A. P. Being responsible: Boards are reexamining the bottom line. Leadership in Action, New Jersey, v. 27, n. 1, p. 3-6, 2007. DOI: https://doi.org/10.1002/lia.1191.

KARTIKEYAN, S.; PRIYADARSHINI, S. Missing women in the boardrooms: Across the board. Human Resource Management International Digest, Bingley, v. 25, n. 5, p. 4-6, 2017. DOI: https://doi.org/10.1108/HRMID-04-2017-0062.

KNOEPFEL, I. Dow Jones Sustainability Group Index: A global benchmark for corporate sustainability. Corporate Environmental Strategy, United States, v. 8, n. 1, p. 6-15, 2001. DOI: https://doi.org/10.1016/S1066-7938(00)00089-0.

KOEHN, N. The brain - and soul - of capitalism. Harvard Business Review, v. 91, n. 2, p. 44, 2013.

KOLK, A. Sustainability, accountability and corporate governance: Exploring multinationals' reporting practices. Business Strategy and the Environment, New Jersey, v. 17, n. 1, p. 1-15, 2008. DOI: https://doi.org/10.1002/bse.511.

LAMEIRA, V. J.; NESS JR., W. L.; QUELHAS, O. L. G.; PEREIRA, R. G. Sustainability, value, performance and risk in the Brazilian capital markets. Revista Brasileira de Gestão e Negócios, São Paulo, v. 15, n. 46, p. 76-90, 2013. DOI: https://doi.org/10.7819/rbgn.v15i46.1302.

LAZONICK, W.; O'SULLIVAN, M. Maximizing shareholder value: A new ideology for corporate governance. Journal Economy and Society, New York, v. 29, n. 1, p. 13-35, 2000. DOI: https://doi.org/10.1080/030851400360541.

LIMA, L. C.; DOMINGOS, S. R. M.; VASCONCELOS, A. C.; REBOUÇAS, S. M. D. P. Reputação e qualidade da governança corporativa das companhias abertas brasileiras. Revista de Administração Faces Journal, Belo Horizonte, v. 14, n. 2, p. 8-43, 2015. DOI: https://doi.org/10.21714/1984-6975FACES2015V14N2ART2034.

LINNENLUECKE, M. K.; GRIFFITHS, A. Corporate sustainability and organizational culture. Journal of World Business, Amsterdam, v. 45, n. 4, p. 357-366, 2010. DOI: https://doi.org/10.1016/j.jwb.2009.08.006.

LOPES, A. C.; DE LUCA, M. M. M.; GÓIS, A. D.; VASCONCELOS, A. C. Disclosure socioambiental, reputação corporativa e criação de valor nas empresas listadas na BM\&FBovespa. Revista Ambiente Contábil, Natal, v. 9, n. 1, p. 364-382, 2017.

MACHADO FILHO, C. P. Responsabilidade social e governança: o debate e as implicações: responsabilidade social, instituições, governança e reputação. São Paulo: Pioneira Thomson Learning, 2006.

MACHADO, M. R.; MACHADO, M. A. V.; CORRAR, L. J. Desempenho do Índice de Sustentabilidade Empresarial (ISE) da bolsa de valores de São Paulo. Revista Universo Contábil, Blumenau, v. 5, n. 2, p. 24-38, 2009. DOI: http://dx.doi.org/10.4270/ruc. 20095. 
Ítalo Carlos Soares do Nascimento, Adriano Fleck de Paula Pessoa, Alessandra Carvalho de Vasconcelos e Márcia Martins Mendes de Luca

MAHMOOD, Z.; KOUSER, R.; ALI, W.; AHMAD, Z.; SALMAN, T. Does corporate governance affect sustainability disclosure? A mixed methods study. Sustainability, New York, v. 10, n. 1, p. 1-20, 2018. DOI: https://doi.org/10.3390/su10010207.

MCDONALD, D.; PUXTY A. G. An inducement-contribution approach to corporate financial reporting. Accounting, Organizations \& Society, Amsterdam, v. 4, n. 1-2, p. 53-65, 1979. DOI: https://doi.org/10.1016/0361-3682(79)90007-2.

MEMON, A.; AKRAM, W.; ABBAS, G. Women participation in achieving sustainability of microfinance institutions (MFIs). Journal of Sustainable Finance \& Investment, Cambridge, v. 21, n. 2, p. 1-19, 2020. DOI: https://doi.org/10.1080/20430795.2020.1790959.

MICHELON, G.; PARBONETTI, A. The effect of corporate governance on sustainability disclosure. Journal of Management \& Governance, New York, v. 16, n. 3, p. 477-509, 2012. DOI: https://doi.org/10.1007/s10997-010-9160-3.

MINUSSI, J. A.; DAMACENA, C.; NESS JR; W. L. Um modelo de previsão de solvência utilizando regressão logística. Revista de Administração Contemporânea, Maringá, v. 6, n. 3, p. 109-128, 2002. DOI: https://doi.org/10.1590/S1415-65552002000300007.

NIELSEN, S.; HUSE, M. The contribution of women on boards of directors: Going beyond the surface. Corporate Governance: An International Review, New Jersey, v. 18, n. 2, p. 136148, 2010. DOI: https://doi.org/10.1111/j.1467-8683.2010.00784.x.

NISIYAMA, E. K.; NAKAMURA, W. T. Diversidade do conselho de administração e a estrutura de capital. Revista de Administração de Empresas, São Paulo, v. 58, n. 6, p. 551-563, 2018. DOI: https://doi.org/10.1590/S0034-759020180604.

PATHAK, A. A.; PURKAYASTHA, A. More women on Indian boards: Moving beyond mere regulations and tokenism. Strategic Direction, Bingley, v. 32, n. 3, p. 13-15, 2016. DOI: https://doi.org/10.1108/MD-07-2017-0690.

PLETZER, J. L.; NIKOLOVA, R.; KEDZIOR, K. K.; VOELPEL, S. C. Does gender matter? Female representation on corporate boards and firm financial performance - A meta-analysis. Plos one, California, v. 10, n. 6, p. 1-20, 2015. DOI:

https://doi.org/10.1371/journal.pone.0130005.

RODRÍGUEZ-ARIZA, L.; CUADRADO-BALLESTEROS, B.; MARTÍNEZ-FERRERO, J.; GÁRCIASÁNCHEZ, I. M. The role of female directors in promoting CSR practices: An international comparison between family and non-family businesses. Business Ethics: A European Review, New Jersey, v. 26, n. 2, p. 162-174, 2017. DOI: https://doi.org/10.1111/beer.12140.

ROSE, C. Does female board representation influence firm performance? The Danish evidence. Corporate Governance, New Jersey, v. 15, n. 2, p. 404-413, 2007. DOI: https://doi.org/10.1111/j.1467-8683.2007.00570.x. 
Participação feminina no conselho de administração e a sustentabilidade empresarial

ROSSETTI, J. P.; ANDRADE, A., J. P. Governança corporativa: fundamentos, desenvolvimento e tendências. 7. ed. São Paulo: Atlas, 2014.

SIAL, M.; ZHENG, C.; CHERIAN, J.; GULZAR, M. A.; THU, P. A.; KHAN, T.; KHOUNG, N. V. Does corporate social responsibility mediate the relation between boardroom gender diversity and firm performance of Chinese listed companies? Sustainability, New York, v. 10, n. 10, p. 1-18, 2018. DOI: https://doi.org/10.3390/su10103591.

SILVA JÚNIOR, C. P.; MARTINS, O. Mulheres no conselho afetam o desempenho financeiro? Uma análise da representação feminina nas empresas listadas na BM\&FBOVESPA. Sociedade, Contabilidade e Gestão, Rio de Janeiro, v. 12, n. 1, p. 62-76, 2017. DOI: https://doi.org/10.21446/scg_ufrj.v12i1.13398.

SPEZAMIGLIO, B. S.; GALINA, S. V. R.; CALIA, R. C. Competitividade, inovação e sustentabilidade: uma inter-relação por meio da sistematização da literatura. REAd - Revista Eletrônica de Administração, Porto Alegre, v. 84, n. 2, p. 363-393, 2016. DOI: https://doi.org/10.1590/1413-2311.009162016.62887.

TONOLLI, B. B.; ROVER, S.; FERREIRA, D. D. M. Influência dos investimentos ambientais e dos indicadores econômico-financeiros na seleção de empresas para compor o índice de sustentabilidade empresarial - ISE. Revista Catarinense da Ciência Contábil, Florianópolis, v. 16, n. 48, p. 69-85, 2017. DOI: http://dx.doi.org/10.16930/2237-7662/rccc.v16n48.2315.

VIVIERS, S.; MANS-KEMP, N.; FAWCETT, R. Mechanisms to promote board gender diversity in South Africa. Acta Commercii, New York, v. 17, n. 1, p. 1-10, 2017. DOI: https://doi.org/10.4102/ac.v17i1.489.

WESTPHAL J. D.; ZAJAC, E. J. Who shall govern? CEO/board power, demographic similarity, and new director selection. Administrative Science Quarterly, Cambridge, v. 40, n. 1, p. 6083, 1995. DOI: https://doi.org/10.2307/2393700.

YAP, I.; CHAN, S.; ZAINUDIN, R. Gender diversity and firms' financial performance in Malaysia. Asian Academy of Management Journal of Accounting and Finance, Asia, v. 13, n.1 p. 41-62, 2017. DOI: https://doi.org/10.21315/aamjaf2017.13.1.2. 